archives

of thermodynamics

Vol. 38(2017), No. 1, 123-139

DOI: $10.1515 /$ aoter-2017-0007

\title{
Determination of dryout localization using a five-equation model of annular flow for boiling in minichannels
}

\author{
JAN WAJS* \\ DARIUSZ MIKIELEWICZ
}

\begin{abstract}
Gdansk University of Technology, Faculty of Mechanical Engineering, Department of Energy and Industrial Apparatus, Narutowicza 11/12, 80-233 Gdańsk, Poland
\end{abstract}

\begin{abstract}
Detailed studies have suggested that the critical heat flux in the form of dryout in minichannels occurs when the combined effects of entrainment, deposition, and evaporation of the film make the film flow rate go gradually and smoothly to zero. Most approaches so far used the mass balance equation for the liquid film with appropriate formulations for the rate of deposition and entrainment respectively. It must be acknowledged that any discrepancy in determination of deposition and entrainment rates, together with cross-correlations between them, leads to the loss of accuracy of model predictions. Conservation equations relating the primary parameters are established for the liquid film and vapor core. The model consists of three mass balance equations, for liquid in the film as well as two-phase core and the gas phase itself. These equations are supplemented by the corresponding momentum equations for liquid in the film and the two-phase core. Applicability of the model has been tested on some experimental data.
\end{abstract}

Keywords: Dryout; Flow boiling; Minichannels

\section{Nomenclature}

\author{
$A \quad-\quad$ cross section area, $\mathrm{m}^{2}$ \\ $C$ - droplet concentration in core, $\mathrm{kg} / \mathrm{m}^{3}$
}

${ }^{*}$ Corresponding Author. E-mail: janwajs@pg.gda.pl 


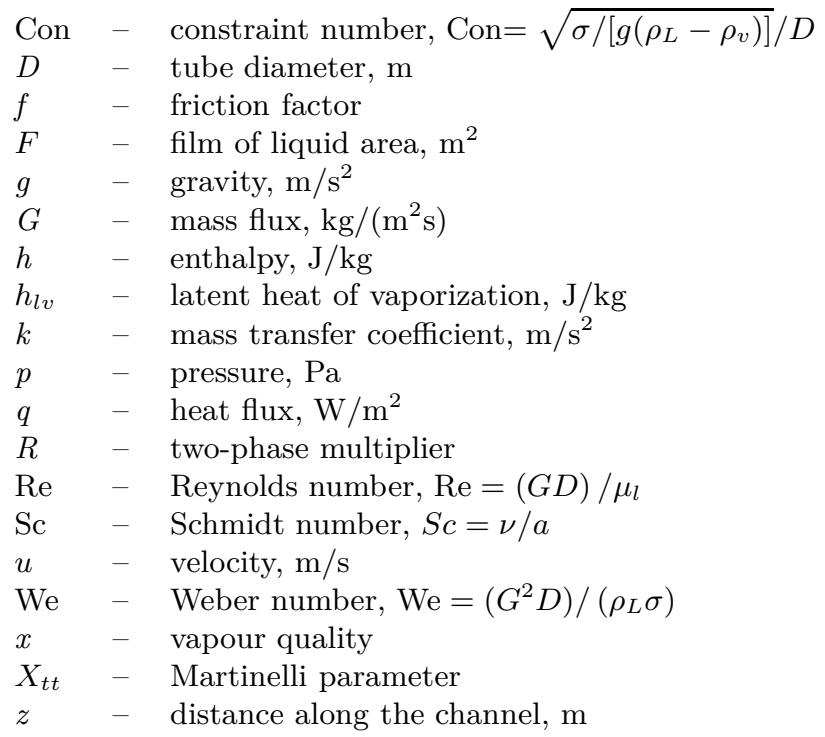

\section{Greek symbols}

$\Gamma \quad-\quad$ evaporation term, $\Gamma=q_{i} / h_{l v}$

$\delta \quad-\quad$ thickness of liquid film, $\mathrm{m}$

$\rho \quad-$ density, $\mathrm{kg} / \mathrm{m}^{3}$

$\mu \quad-\quad$ dynamic viscosity, $\mathrm{Pa} / \mathrm{s}$

$\nu \quad-$ kinematic viscosity, $\mathrm{m}^{2} / \mathrm{s}$

$\sigma \quad-\quad$ surface tension, $\mathrm{N} / \mathrm{m}$

$\tau \quad-\quad$ shear stresses, $\mathrm{N} / \mathrm{m}^{2}$

$\zeta \quad-$ drag coefficient

\section{Superscripts and subscripts}

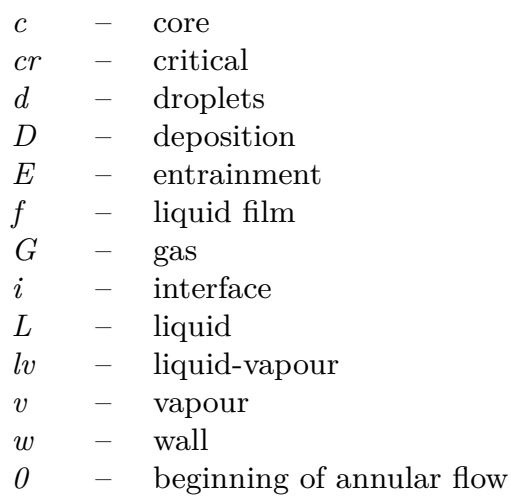




\section{Introduction}

Dryout condition represents the termination of the continuous liquid contact with the heated surface in a flow channel at moderate to high qualities. It follows the gradual decrease of liquid fraction due to evaporation or boiling of the liquid film. At this point, the liquid film at the heated surface dries up, while entrained droplets may still flow in the vapor core. These droplets occasionally hit the heated surface and evaporate. Dryout occurs, independently of the heat flux, at high vapor qualities and small to moderate mass fluxes. The flow pattern before the dryout condition is annular with the vapor phase occupying most of the channel core while the liquid flows as a thin film along the channel wall [1].

Dryout occurrence depending on various parameters was (and still is) a subject of extensive experimental and theoretical analysis. Researchers placed a lot of efforts to get the results of dryout dependence on the applied working fluid, mass flow rate, saturation temperature, vapour quality, etc. Mikielewicz et al. [2] reported the experimental results regarding four fluids in two small diameter tubes. They observed that dryout heat flux increased with: (1) increase of mass velocity, (2) decrease of vapor quality and (3) increase of tube diameter. On the basis of experimental results they proposed the correlation for prediction of critical heat flux (CHF) in the minichannels.

Anwar et al. [3,4] described the experimental investigations of numerous natural and synthetic refrigerants in the flow boiling and dryout regions in the stainless steel single minitube. They examined various operational conditions to assess the prediction of macro and micro scale correlations from literature. With some correlation good agreement was obtained but with the others quite poor. Markedly, a very good agreement has been found with the correlation for minichannels due to Mikielewicz et al. [2]. Additionally, they proposed their own correlation for prediction of heat flux at dryout conditions.

The critical heat flux was a subject of studies by Mastrullo et al. $[5,6]$. In both cases the low-low global warming potential (GWP) fluids were analyzed. Their test section consisted of seven aluminum rectangular minichannels. In [5] investigated was the influence of mass flux and saturation temperature on the boiling curve and critical heat flux and compared the results with published correlations. It could be again observed, that some of the correlations in better way predicted the critical heat flux than the others. Authors observed that CHF significantly increased with increasing 
mass flux, while it dropped down with increasing saturation temperature. In [6] the effect of geometry was also taken into account. It was reported that increasing heating length to hydraulic diameter ratio reduced critical heat flux at low mass velocity values, while at it higher values the effect was opposite.

New approach to the subject was proposed by Anglart et al. [7], who described application of computational fluid dynamics to prediction of dryout and post-dryout heat transfer. They applied the three field model accounting for droplets, gas and liquid film to simulate pre and post dryout. This model was unified with the local model (critical film thickness model) to determine the dryout occurrence. Presented results depicted in general a good agreement with the experimental data on the dryout location and wall temperature distribution. However, this approach still requires an improvement, especially within local models.

These experimental and numerical analyses exhibited complexity of the phenomena, which depend on many parameters and if the good prediction for particular case could be done, change of operating conditions breaks down the correspondence. Therefore, the efforts still should be placed on the understanding and modeling of dryout.

Since the examples of applications range from superheaters of supercritical cycles to refrigeration technology the analysis starts up from the point where quality is high and the flow pattern is annular. Detailed studies have suggested that the critical heat flux occurs when the combined effects of entrainment, deposition, and the evaporation of the film make the film flow rate go gradually and smoothly to zero. The mass balance in film flow analysis is one of the successful prediction methods of the dryout in flow boiling. Most approaches so far used the mass balance equation for the liquid film with appropriate formulations for the rate of deposition and the rate of entrainment. Examples of such mass balance models are due to Okawa [8] and Celata [9]. It must be acknowledged that any discrepancy in determination of deposition and entrainment rates, together with crosscorrelations between them, leads to loss of accuracy of model predictions.

Celata [9] basing on the balance of liquid film in the channel applied a one-equation model due to Whalley [10] to determine CHF in small diameter channels. In such model modified were the terms related to entrainment and deposition of droplets suspended in the channel core. The deposition term has been modeled in line with the model due to Kataoka and Ishii [11], whereas the entrainment term has been considered in the form of two 
contributions, namely the term related to droplet entrainment as a result of boiling of liquid; that was modelled in line with the Ueda relation [12] and the second term is related to breakup of rolling waves on the film interface. That term was modeled using the Kataoka and Ishii model [11]. The beginning of the annular flow was determined using the Mishima and Ishii relation [13] in channels with diameters ranging from 1-6 mm.

A two-equation approach has been postulated by Sedler and Mikielewicz [14] with some further modifications by Mikielewicz et al. [15]. An analytical model was developed where the mass balance equation in the film is supplemented with the mass balance equation for entrained droplets in the core. Such approach is more general, as two variables, namely the mass velocity of film and mass velocity of droplets are solved by two independent equations. One of the distinct features of the approach presented by Sedler and Mikielewicz was that the ratio of entrained droplets with respect to the amount of liquid was used. Originally their approach was to assume that the rate of deposition, $G_{D}$, is proportional to flow rate of entrained droplets in the core, whereas the rate of entrainment was also proportional to the flow rate of liquid in the film. Such assumption enabled to find very simple analytical solution of liquid film flow rate distribution.

Gliński [16] postulated a three-equation model where the balance equation in the film is supplemented with the mass balance equation for mixture of entrained droplets and gas in the core. Such approach is more general, and its major advantage over a two-equation model due to Sedler and Mikielewicz [14] does not require manual split of liquid into film and the entrained droplets. It was also applied in the model mentioned by Anglart [7] in the numerical model of dryout.

The fundamental problem with modeling of liquid balance in the film is adequate determination of initial conditions. Such conditions require appropriate mass velocity of liquid droplets in the core, $G_{d}$, as well as the mass velocity of liquid film on the channel wall $G_{f}$, at the beginning of annular flow. That together with the simplified descriptions of the momentum equations for liquid and vapour in conventional size tubes have been the topic of the work presented in [17].

In the present study the five-equation model of dryout in the annular flow in minichannels is proposed. The mass balance of liquid equations in the film and core, together with mass balance of vapour in the core are supplemented by the simplified momentum equations creating five-equations model. In the case of minichannels, where mainly laminar flow case is 
present there are no waves on the liquid film. Therefore the entrainment, which must be present in the case of turbulent flows, can be neglected.

\section{Five-equation model of dryout}

The five-equation model is based on the liquid balance in the film and in the core (droplets in the core) and also the vapor balance in the core of the annular flow. These equations are supplemented by equations of momentum balance in liquid film and vapour core. The model is dedicated to determination of the dryout location in minichannels. The following assumptions have been postulated in the development of the model:

- onset of annular flow is known;

- liquid film flow is laminar;

- liquid-vapor interface is stable, therefore the influence of surface tension is large;

- pressure drop in liquid film is the same as in the vapour phase, i.e. no film curvature effects;

- no entrainment of droplets from the liquid film $\mathrm{G}_{E}$, what was also used by Qu and Mudawar [18].

Figure 1 illustrates the general picture of annular flow in the minichannel tube. The vapor phase flows as a continuous vapor core with the suspended droplets. The liquid phase is comprised of two contributions: droplets that are suspended in the vapor core and the liquid film on the channel wall. The simplified geometrical representation of annular flow illustrated in Fig. 1 denotes the continuous liquid film flowing on the wall, having a laminar character. The liquid film exchanges mass with the twophase core by means of surface evaporation of the film and deposition of droplets from the core. The liquid film mass flux, $\mathrm{G}_{f}$, the core mass flux, $G_{c}$, the gas mass flux in the core, $G_{G}$, film thickness, $\delta$, interfacial shear stress, $\tau_{i}$, and pressure gradient, $-(\mathrm{d} p / \mathrm{d} z)$, constitute the five primary parameters for the annular two-phase flow model. Equations relating the primary parameters are established by application of fundamental conservation equations to both the liquid film and vapor core.

The model consists of three mass balance equations, namely for liquid in the film as well as for the two-phase core containing droplets and the gas phase itself. These equations are supplemented by the corresponding momentum equations: 


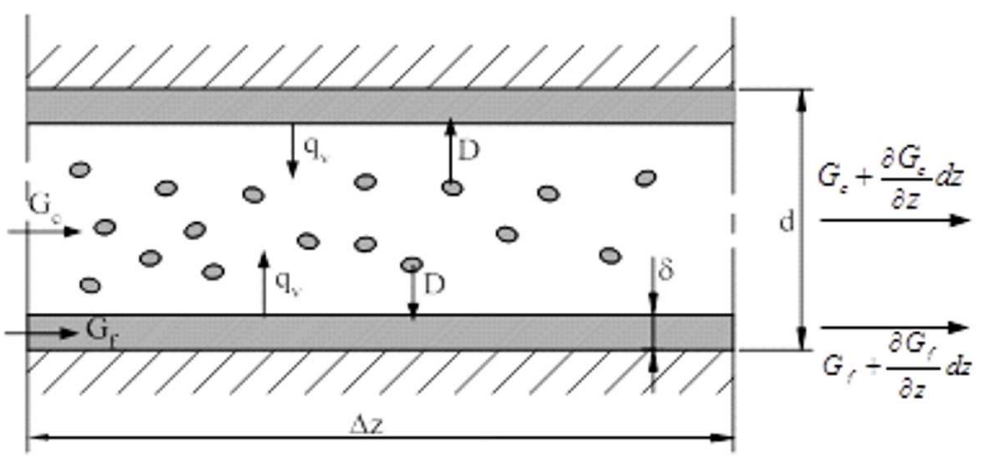

Figure 1: Schematic of annular flow with boiling.

The mass balance equation of liquid in the core

$$
d G_{c} A_{c}=\left(\Gamma-G_{D}\right) F_{f},
$$

where $A_{c}$ is the cross section area of the core and $F_{f}$ is the area of the film on which evaporation and deposition take place, $\Gamma$ is the evaporation term. After substituting relevant terms we obtain

$$
d G_{c} \frac{\pi(D-2 \delta)^{2}}{4}=\left(\frac{q_{i}}{h_{l v}}-G_{D}\right) \pi D d z,
$$

which reads after rearrangements

$$
\frac{d G_{c}}{d z}=\frac{4}{D}\left(\frac{q_{i}}{h_{l v}}-G_{D}\right) \frac{1}{\left(1-\frac{2 \delta}{D}\right)^{2}}
$$

The mass balance equation of liquid in the film

$$
d G_{f} A_{f}=\left(G_{D}-\Gamma\right) F_{f},
$$

which results in

$$
d G_{f} \frac{\pi\left[D^{2}-(D-2 \delta)^{2}\right]}{4}=\left(G_{D}-\frac{q_{i}}{h_{l v}}\right) \pi D d z,
$$

which reads after rearrangements

$$
\frac{d G_{f}}{d z}=\frac{4}{D}\left(G_{D}-\frac{q_{i}}{h_{l v}}\right) \frac{1}{1-\left(1-\frac{2 \delta}{D}\right)^{2}} .
$$


The mass balance equation of gas in the core

$$
d G_{G} A_{c}=\frac{q_{i}}{h_{l v}} F_{f},
$$

which results in

$$
d G_{G} \frac{\pi(D-2 \delta)^{2}}{4}=\frac{q_{i}}{h_{l v}} \pi D d z,
$$

which reads after re-arrangements

$$
\frac{d G_{G}}{d z}=\frac{4}{D} \frac{q_{i}}{h_{l v}} \frac{1}{\left(1-\frac{2 \delta}{D}\right)^{2}},
$$

The momentum balance equation of liquid in the film At first the attention is placed on the film, a schematic of which is shown in Fig. 2.

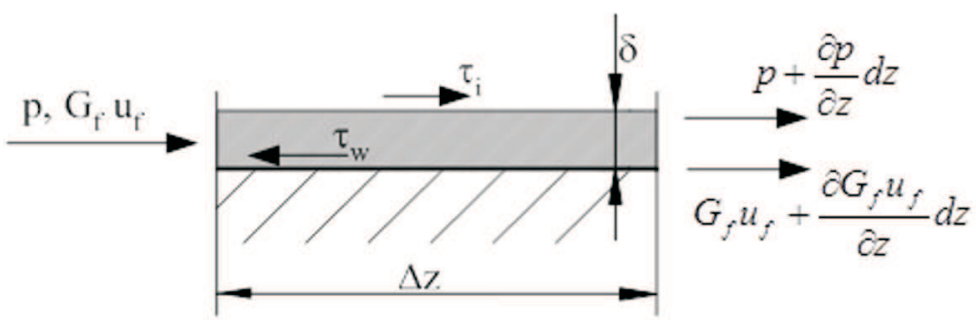

Figure 2: Schematic of forces acting on the film.

The force balance on the element of film yields

$$
\begin{gathered}
{\left[p-\left(p+\frac{\partial p}{\partial z} d z\right)\right] \pi D \delta+\left(\tau_{i}-\tau_{w}\right) \pi d z+} \\
{\left[\left(G_{f} u_{f}+\frac{\partial\left(G_{f} u_{f}\right)}{\partial z}\right)-G_{f} u_{f}\right] \pi D \delta=0}
\end{gathered}
$$

which after necessary rearrangements can be reduced to the form

$$
-\frac{\partial p}{\partial z}+\frac{\tau_{i}-\tau_{w}}{\delta}+\frac{d}{d z}\left(\frac{G_{f}^{2}}{\rho_{f}}\right)=0 .
$$


The momentum balance equation of gas and liquid in the core Considered core of the flow is shown in Fig. 3.

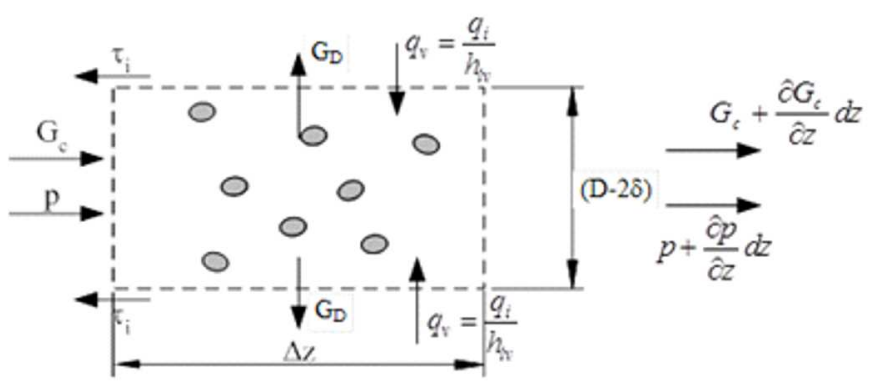

Figure 3: Schematic of the forces acting on the core of the flow.

The force balance on the element of core yields

$$
\begin{aligned}
& {\left[p-\left(p+\frac{\partial p}{\partial z} d z\right)\right] \frac{\pi(D-2 \delta)^{2}}{4}-\tau_{i} \pi(d-2 \delta) d z+} \\
& \quad\left[\left(G_{c} u_{c}+\frac{\partial\left(G_{c} u_{c}\right)}{\partial z} d z\right)-G_{c} u_{c}\right] \frac{\pi(D-2 \delta)^{2}}{4}=0,
\end{aligned}
$$

which can be reduced to the form:

$$
-\frac{\partial p}{\partial z}-\frac{4 \tau_{i}}{(D-2 \delta)}+\frac{\partial}{\partial z}\left(\frac{G_{c}^{2}}{\rho_{c}}\right)=0 .
$$

Determination of film thickness from Eqs. (1)-(5) enables to determine the dryout location. At this stage the attention is focused on determination of the liquid film thickness, which is decreasing as a result of liquid film evaporation. In order to do that it is necessary to scrutinize the momentum equations, as the equation for the film is subtracted from the one for the core. That eliminates the pressure gradient term present in both equations. Then following equation can be obtained:

$$
\frac{d}{d z}\left(\frac{G_{c}^{2}}{\rho_{c}}-\frac{G_{f}^{2}}{\rho_{f}}\right)=\frac{\tau_{i}-\tau_{w}}{\delta}+\frac{4 \tau_{i}}{(D-2 \delta)} .
$$

Equation (7) can be solved to obtain the unknown film thickness distribution

$$
1+\frac{4 \delta}{D-2 \delta}=\frac{\tau_{w}}{\tau_{i}}-\frac{\delta}{\tau_{i}} \frac{d}{d z}\left(\frac{G_{c}^{2}}{\rho_{c}}-\frac{G_{f}^{2}}{\rho_{f}}\right) .
$$


Below, a brief recapitulation of closure equations, used in calculations is presented.

Closure equations and working equations The total mass flux, $G$, in the minichannel is the sum of mass fluxes of the liquid film, $G_{f}$, liquid droplet, $G_{d}$, and vapor core $G_{G}$

$$
G=G_{f}+G_{d}+G_{G} .
$$

Heat flux distribution The term related to evaporation of liquid film, which contains the heat flux has been assumed according to [15]. The equation for heat flux distribution across the film yields

$$
q_{i}=q_{w}\left[1-\left(\frac{D-2 \delta}{D}\right)\right] .
$$

Location of beginning of annular flow The criterion for the transition to annular flow in tubes proposed by Taitel and Dukler [19] was used to determine the location of the onset of annular flow. This criterion uses a constant value for the Martinelli parameter at the transition point. The value $X_{t t}=1.6$, as the $\mathrm{Qu}$ and Mudawar [18] reported. The Martinelli parameter for the combination of laminar liquid and laminar vapor flow rate is given by

$$
X_{t t}=\left[\frac{\mu_{L}}{\mu_{G}}\left(\frac{1-x_{0}}{x_{0}}\right) \frac{\nu_{L}}{\nu_{G}}\right]^{0.5} .
$$

Next important parameter is distribution of liquid amongst the liquid film and vapor core. The total mass velocity is used for that purpose with following relations

- amount of droplets at the beginning of annular flow [18]

$$
G_{d}=x G+(0.951-0.15 \sqrt{\mathrm{We})},
$$

- amount of gas at the beginning of annular flow

$$
G_{G}=G x,
$$

- mass balance in the core

$$
G_{c}=G_{d}+G_{G},
$$

- amount of liquid in the liquid film

$$
G_{f}=G-G_{c} .
$$


Deposition of droplets Denoting the concentration of droplets in gas core by $C$ and the deposition mass transfer coefficient by $k_{D}$, the rate of droplet deposition, $\mathrm{G}_{D}$ is defined by the relation

$$
G_{D}=k_{D} C .
$$

Current research is based on empirical methods to determine the deposition mass transfer coefficient, $k_{D}$, due to the complexity of this phenomenon, using the correlation expressed as follows [8]

$$
\frac{k_{D}}{J_{G}}=0.009\left(\frac{C}{\rho_{G}}\right)^{-0.5} \operatorname{Re}_{G}^{-0.2} \mathrm{Sc}^{-\frac{2}{3}}
$$

where $J_{G}=G_{G} / \rho_{G}$ is vapor superficial velocity, $C$ is the liquid droplet concentration in the vapor core and Sc Schmidt number. Liquid droplet concentration in the vapor core was defined as

$$
C=\frac{G_{c}-G_{G}}{\frac{G_{G}}{\rho_{G}}+\frac{G_{c}+G_{G}}{\rho_{L}}} .
$$

\section{Solution procedure for determination of location of dryout}

The model development so far has resulted in devising of a sufficient number of equations to determine local values for all mass flowrates distinguished in our study, i.e., $G_{f}, G_{c}, G_{G}, \delta$, and $\tau_{i}$. Unfortunately, these parameters are interrelated, rendering the equations too complex to be solved analytically. A numerical procedure is therefore developed to solve these equations using the following procedure:

1. Equation (11) is first used to determine the location of the onset (upstream point) of annular flow. The annular flow region in the minichannel is then identified as the length from that location. A special marching procedure with iterations at particular location in commercial software MathCad14 has been developed to enable determination of the location. The initial mass flow rates of the liquid film, liquid droplets, and vapor at the onset of annular flow are evaluated using Eqs. (9), (12)-(15). The solution is initiated from the node next to the upstream boundary node and proceeds downstream: 
- initial film thickness of the annular flow is calculated from relation $\delta_{0}=\frac{G_{f 0} 2 \mu_{L}}{\tau_{w} \rho_{L}}$

- liquid wall shear at the beginning of annular flow $\tau_{w 0}=R_{0} \zeta_{0} \frac{G_{f}^{2}}{8 \rho_{L}}$;

- two-phase flow multiplier at the beginning $R_{0}=1+\frac{\rho_{L}-\rho_{G}}{\rho_{L}} x_{0}$. According to the minichannels the Müller-Steinhagen and Heck correlation [20] should be applied with some modification concerning the Con number [21], as in the following equation: $R_{0}=$ $\left[1+2\left(\frac{1}{f_{1}}-1\right) x_{0} \mathrm{Con}^{-1}\right]\left(1-x_{0}\right)^{1 / 3}+\frac{1}{f_{1 z}} x_{0}^{3}$. In this equation $f_{1}$ and $f_{1 z}$ are the functions which for laminar flow can be expressed as $f_{1}=\frac{\mu_{L}}{\mu_{v}} \frac{\rho_{v}}{\rho_{L}}, f_{1 z}=\frac{\mu_{v}}{\mu_{L}} \frac{c_{L}}{c_{v}}\left(\frac{\lambda_{L}}{\lambda_{v}}\right)^{1.5}$;

- flow resistance coefficient $\zeta_{0}=0.316 \operatorname{Re}_{f}^{-0.25}$.

2. At each node, an initial guess is made for liquid film thickness, $\delta$. All other geometrical parameters in the annular flow region can be evaluated using the tentative $\delta$ value.

3. The interfacial shear stress, $\tau_{i}$, is evaluated from the formula $\tau_{i}=$ $f_{i}\left[\frac{1}{2} \rho_{c}\left(u_{c}-u_{i}\right)^{2}-\frac{q_{i}}{2 h_{l v}}\left(u_{c}-u_{i}\right)\right]$, where the constituting terms are calculated from relations:

- friction factor $f_{i}=0.005\left(1+300 \frac{\delta}{D}\right)$,

- core velocity $u_{c}=\frac{G_{c}}{\rho_{c}}$,

- interfacial velocity $u_{i}=\frac{\tau_{w} \delta}{2 \mu_{L}}$,

- density of vapor core $\rho_{c}=\frac{1}{\frac{G_{G}}{G_{c}} \frac{1}{\rho_{G}}+\left(1-\frac{G_{G}}{G_{c}}\right) \frac{1}{\rho_{L}}}$,

- two other parameters important in the development model are defined as $x_{c}=\frac{G_{G}}{G_{c}}$ and $x=\frac{G_{G}}{G}$, where $x_{c}$ is the effective vapor quality in the vapor core and $x$ - total quality.

4. All other variables in Eq. (8) are evaluated using geometrical parameters determined from step (2) and the mass flow rates from step (3).

5. The solution seeks to balance both sides of Eq. (8). If this criterion is not satisfied, a new value of $\delta$ is assumed and steps (2)-(4) repeated until convergence criterion on liquid film mass velocity, $\mathrm{G}_{f}$, is reached. Then the values of the primary parameters obtained in the last iteration are adopted for that nodal location. 
6. The code then repeats the same numerical procedure for the next downstream node in pursuit of a balance for $G_{f}$ at this new node. This procedure is then repeated by marching downstream until the last node in the annular flow region is reached.

To summarize it can be said that well-characterized experiments that investigate flow regimes and instabilities over a broad range of parameters (fluids, substrates, and geometries) will help to achieve a better understanding of the underlying heat transfer processes on which more realistic models can be based.

\section{Comparison of calculation results with experimental data}

Verification of the model is based on own experiments [2] conducted for minitubes with diameters of $1.15 \mathrm{~mm}$ and $2.3 \mathrm{~mm}$, with ethanol as a test fluid. Obtained experimentally results were compared with predictions of the five-equation model, described above as well as the three-equation model due to Gliński [16].

Figures 4 and 5 present a dependence of the critical length $z_{c r}$ on the vapour quality in critical conditions $x_{c r}$ for chosen values of mass flux. In these figures the five equation model predictions is presented in comparison to experimental data for ethanol for the mass flux values $G=100$ and $200 \mathrm{~kg} /\left(\mathrm{m}^{2} \mathrm{~s}\right)$, for the tube diameter $D=1.15 \mathrm{~mm}$, whereas in Figs. $6-7$ for $G=40$ and $70 \mathrm{~kg} /\left(\mathrm{m}^{2} \mathrm{~s}\right)$ respectively for tube with diameter $D=2.3 \mathrm{~mm}$. During experiments a location of the liquid film dryout in the flow boiling was determined by the infrared technique $[2,22]$. The vapour quality at this location was calculated using the thermal balance from the beginning of the annular flow structure. In figures are also presented the calculations obtained using the three-equation mass balance model due to Gliński [16].

In all presented cases a superiority of the proposed five-equation model over the three-equation model in relation to obtained experimental data can be observed. Better consistency is obtained in case of smaller tube size, i.e., $D=1.15 \mathrm{~mm}$. In that case the superiority of a new model is apparent. In case of the tube with diameter $D=2.3 \mathrm{~mm}$ still the new model returns better consistency but the discrepancy is bigger. In case of the smaller tube the laminar flow conditions were present. 
The reason for a better agreement in case of experimental data for $D=1.15 \mathrm{~mm}$ is that the momentum equation provides a more accurate value of the liquid film thickness, which subsequently enables more accurate determination of the dryout location. Calculations of the dryout location are very sensitive to the selection of the deposition correlation. In the course of the study several models have been tested, but only the correlation due to Sugawara [8] was found to work with the model. Another issue is that obtained in the experiment flow conditions relate to laminar flows, whereas the correlations used for deposition are mostly corresponding to turbulent flow conditions. There is a lack of appropriate correlations for laminar flows. Therefore it can be said that further intense research in that area is necessary. In future the agreement of the presented model of dryout predictions and experimental data can be improved if new and better correlations will be developed for deposition of respective phases.

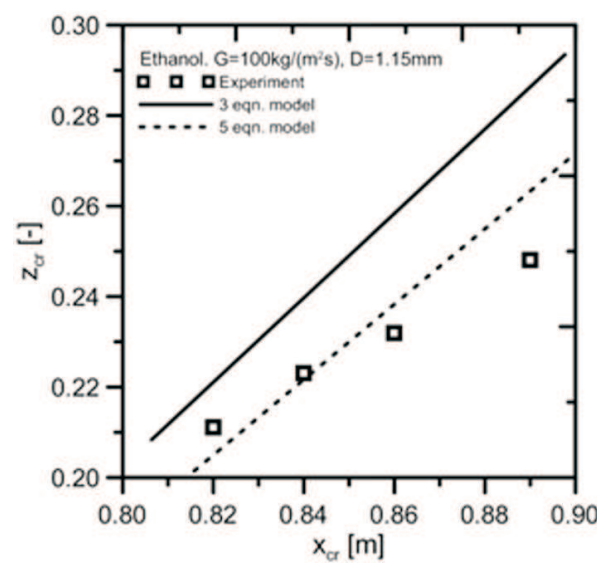

Figure 4: Comparative analysis for ethanol in tube with diameter $\mathrm{D}=1.15 \mathrm{~mm}\left(\mathrm{G}=100 \mathrm{~kg} / \mathrm{m}^{2} \mathrm{~s}\right)$.

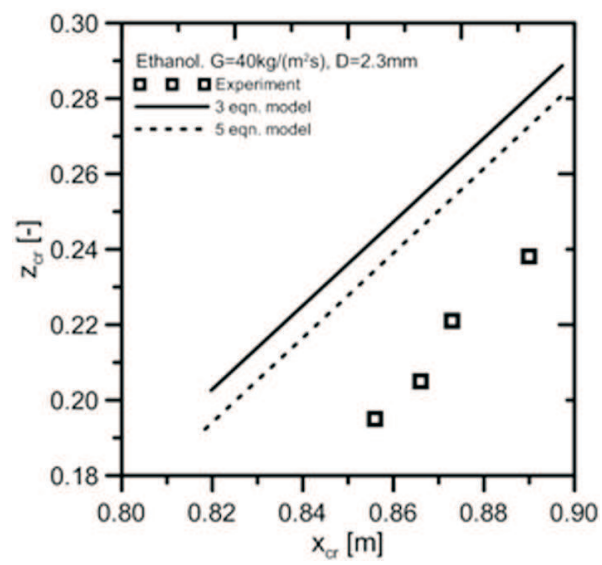

Figure 5: Comparative analysis for ethanol in tube with diameter $\mathrm{D}=1.15 \mathrm{~mm}\left(\mathrm{G}=200 \mathrm{~kg} / \mathrm{m}^{2} \mathrm{~s}\right)$.

\section{Conclusions}

An original five-equation model of dryout in minichannels has been developed and tested. The consideration of momentum equations for the liquid in the film as well as liquid and gas in the core forms a step forward in modeling of dryout in small diameter tubes. The model still requires the refinement, but the idea of its development is original in the literature. 


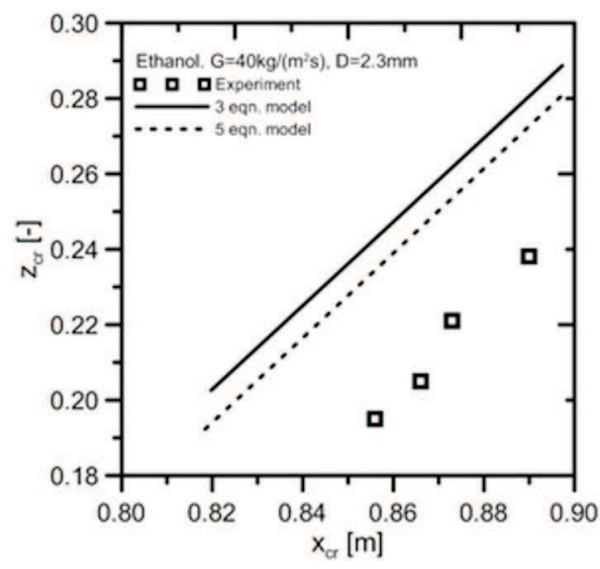

Figure 6: Comparative analysis for ethanol in tube with diameters $D=2.3 \mathrm{~mm}\left(G=40 \mathrm{~kg} / \mathrm{m}^{2} \mathrm{~s}\right)$.

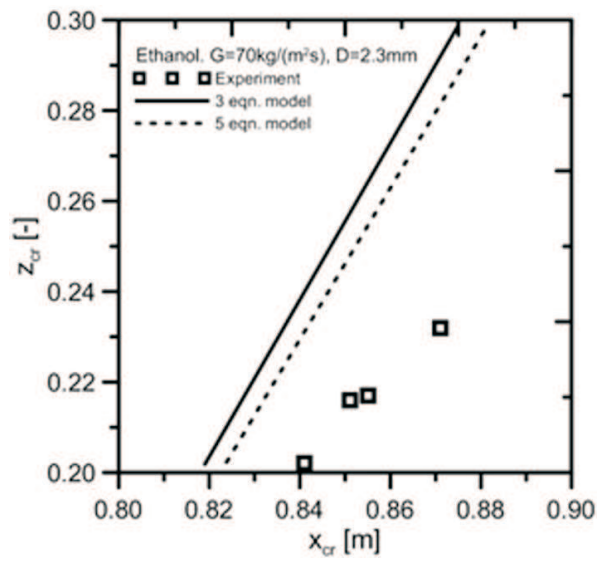

Figure 7: Comparative analysis for ethanol in tubes with diameters $D=1.15 \mathrm{~mm}\left(G=70 \mathrm{~kg} / \mathrm{m}^{2} \mathrm{~s}\right)$.

Inclusion of momentum equations for liquid and vapour leads to a better determination of the liquid film thickness, which is crucial in the correct determination of location of dryout.

The proposed model has been compared with own experimental data for considered minichannels showing a superiority in relation to the threeequation model developed earlier by Gliński [16]. The developed model enables calculation of liquid film thickness and such updated value is used in calculations of mass balance in liquid film and the core.

Received 15 May 2017

\section{References}

[1] Collier J.G., Thome J.R.: Convection boiling and condensation, 3rd Edn. McGraw-Hill, New York 1994.

[2] Mikielewicz D., Wajs J., Gliński M., Zrooga A-B.R.S.: Experimental investigation of dryout of SES 36, R134a, R123 and ethanol in vertical small diameter tubes. Exp. Therm. Fluid Sci. 44(2013), 556-564.

[3] Anwar Z., Palm B., Khodabandeh R: Flow boiling heat transfer and dryout characteristics of R152a in a vertical mini-channel. Exp. Therm. Fluid Sci. 53(2014), 207-217.

[4] Anwar Z., Palm B.E., Khodabandeh R: Dryout characteristics of natural and synthetic refrigerants in single vertical mini-channels. Exp. Therm. Fluid Sci. 68(2015), 257-267. 
[5] Mastrullo R., Mauro A.W., Thome J.R., Vanoli G.P., Viscito L.: Critical heat flux: Performance of R1234yf, R1234ze and R134a in an aluminum multiminichannel heat sink at high saturation temperatures. Int. J. Therm. Sci. 106(2016), $1-17$.

[6] Mastrullo R., Mauro A.W., Viscito L.: Experimental CHF for low-GWP fluids and R134a. Effect of the $L_{h} / D$ ratio at low and high mass velocities. Int. J. Heat Mass Tran. 109(2017), 1200-1216.

[7] Li H., Anglart H.: Prediction of dryout and post-dryout heat transfer using a twophase CFD model. Int. J. Heat Mass Tran. 99(2016), 839-850.

[8] Okawa T., Kotani A., Kataoka I., Naito M.: Prediction of the critical heat flux in annular regime in various vertical channels., Nucl. Eng. Des. 229(2004), 2-3, 223-236.

[9] Celata G.P., Mishima K., Zummo G.: Critical heat flux for saturated flow boiling of water in vertical tubes. Int. J. Heat Mass Tran. 44(2001), 22, 4323-4331.

[10] Whalley P.B, Hutchinson P., Hewitt G.F.: The calculation of critical heat flux in forced convection boiling. Proc. 5th Int. Heat Transfer Conf., B6.11, 290-294, 1974.

[11] KataokA I., Ishin M.: Mechanism and correlation of droplet entrainment and deposition in annular two-phase flow. Nuclear Regulatory Commision NUREG/CR 2885, ANL 82-44, 1982.

[12] Ueda T., Inoue M., Nagatome S.: Critical heat flux and droplet entrainment rate in boiling of falling liquid films. Int. J. Heat Mass Tran. 24(1981), 7, 1257-1266.

[13] Mishima K., Ishis M.: Flow regime transition criteria for upward two-phase flow in vertical tubes. Int. J. Heat Mass Tran. 27(1984), 5, 723-737.

[14] Sedler B., Mikielewicz J.: A simplified model of the boiling crisis. Int. J. Heat Mass Tran. 24(1981), 3, 431-438.

[15] Mikielewicz D., Mikielewicz J., Wajs J., Gliński M.: Modelling of dryout process in an annular flow. Heat Transf. Res. 39(2008), 7, 587-596 DOI:10.1615/HeatTransRes.v39.i7.30.

[16] Gliński, M.: Study of critical heat flux in small diameter channels, PhD thesis, Gdańsk University of Technology, Gdańsk 2010.

[17] Mikielewicz D., Gliński M., Zrooga A-B.R., Mikielewicz J.: A model of liquid film evaporation in annular flow in minichannels. Proc. 8th ECI Int. Conference on Boiling and Condensation Heat Transfer, Lausanne, 3-7 June 2012.

[18] Qu W., Mudawar I.: Flow boiling heat transfer in two-phase micro channel heat sinks - II. Annular two-phase flow model. Int. J. Heat Mass Tran. 46(2003), 15, $2773-2784$.

[19] Taitel Y., Dukler A.E.: A model for predicting flow regime transitions in horizontal and near horizontal gas-liquid flow. AIChE J. 22(1976), 1, 47-55.

[20] Müller-Steinhagen R., Heck K.: A simple friction pressure drop correlation for two-phase flow in pipes. Chem. Eng. Progress 20(1986), 6, 297-308. 
[21] Mikielewicz D., Mikielewicz J.: A common method for calculation of flow boiling and flow condensation heat transfer coefficients in minichannels with account of nonadiabatic effects. Heat Transfer Engineering 32(2011), 13-14, 1173-1181.

[22] Mikielewicz D., Wajs J., Gliński M., Mikielewicz J.: Thermovisual investigation of dryout process in annular flow. International Symposium on Convective Heat and Mass Transfer in Sustainable Energy (CONV-09), Hammamet, 26.04-1.05.2009. (DOI:10.1615/ICHMT.2009.CONV.1310). 